\title{
Frequency of Primary Hyperaldosteronism in Young Hypertensives in a Tertiary Care Setting of Rawalpindi
}

\author{
Mehwish Gilani1, Naveed Asif1, Asif Nawaz and Ammad Akram²
}

\begin{abstract}
Objective: To determine the frequency of primary hyperaldosteronism in young hypertensives in hospital settings of Rawalpindi.

Study Design: Cross-sectional study.

Place and Duration of Study: Department of Chemical Pathology and Endocrinology, Armed Forces Institute of Pathology (AFIP), Rawalpindi, from June 2016 to May 2017.

Methodology: Two hundred and fifty patients with hypertension (blood pressure of more than 140/90 mm $\mathrm{Hg}$ ) of both genders, with age between 17-40 years were recruited in the study. Patients on anti-hypertensive medications, renal function derangement, pregnant females and those labelled with secondary hypertension were excluded. Blood samples were taken for the analyses of plasma renin, aldosterone, electrolytes, and blood gases. Parametric quantitative variables were presented as mean \pm SD.

Results: Eight cases, out of a total 80 subjects fulfilling the inclusion criteria, were diagnosed with primary hyperaldosteronism and 72 with essential hypertension. Mean age of patients having primary hyperaldosteronism was $29.25 \pm 7.1$ years. The mean diastolic blood pressure of all patients was $90.3 \pm 6.5 \mathrm{~mm}$ of $\mathrm{Hg}$, while mean systolic blood pressure was $142.7 \pm 10.5 \mathrm{~mm}$ of $\mathrm{Hg}$.

Conclusion: Frequency of primary hyperaldosteronism was found to be $10 \%$, emphasising on the fact that it is not very uncommon in young hypertensives.
\end{abstract}

Key Words: Renin angiotensin aldosterone disorders, Primary hyperaldosteronism, Essential hypertension.

\section{INTRODUCTION}

Hypertension is a major health problem worldwide and one of the leading risk factors for cardiovascular diseases. ${ }^{1}$ In developed countries, it comprises of the bulk portion of the non-communicable diseases. 2,3 In the younger population, the prevalence of hypertension is $20 \%$ in men and $15 \%$ in women. ${ }^{4}$ Extensive work has been done on this subject and a lot of data has been collected, but still the relationship between kidneys and hypertension remains an enigma. It has been termed as the villain victim relationship, with hypertension being both a cause and a consequence of kidney disease. ${ }^{5}$

Renin-Angiotensin-Aldosterone System (RAAS) has an important role in maintaining hemodynamic stability by regulating the water and electrolyte balance, arterial blood pressure and systemic vascular resistance. ${ }^{6}$ In case of hypotension, renin is released from kidneys while liver release angiotensinogen in blood, resulting in

1 Department of Chemical Pathology, Armed Forces Institute of Pathology (AFIP), Rawalpindi, Pakistan

2 Department of Medicine, Military Hospital, Rawalpindi, Pakistan

Correspondence: Dr. Mehwish Gilani, Department of Chemical Pathology and Endocrinology, Armed Forces Institute of

Pathology (AFIP), Rawalpindi, Pakistan

E-mail:drmehwishgilani@hotmail.com

Received: February 26, 2018; Accepted: July 23, 2018 formation of angiotensin I, which forms angiotensin II, ultimately leading to the secretion of aldosterone from adrenal glands. Aldosterone, in turn, causes sodium reabsorption and potassium excretion from kidneys, returning the blood pressure to normal. 7,8 Chronic activation of RAAS by any pathological mechanism results in excessive vasoconstriction, resulting in the development of hypertension. ${ }^{9}$ RAAS disorders, which present with hypertension, include primary hyperaldosteronism, Liddle syndrome, Gordon syndrome, and apparent mineralocorticoid excess syndrome. 10-14

Conn described PHA for the first time in 1954. The cardinal signs are hypertension and hypokalemia and metabolic alkalosis; but potassium levels can be found normal in some cases. The most common causes include aldosterone producing adenomas, and bilateral adrenal hyperplasia. Less common forms can be familial hyperaldosteronism types I, II, III, adrenocortical carcinomas (pure aldosterone producing), adrenal hyperplasia, ectopic tumors producing aldosterone. PHA is the leading hormonal cause of hypertension with a prevalence of almost 5\% in Asian population, 15 and $4.6 \%$ to $16.6 \%$ among Greeks. 10 Extended screening is required for the patients of PHA because early diagnosis facilitates an effective treatment. Plasma aldosterone concentration to plasma renin activity ratio (PAC/PRA) has been employed as the most common screening test. This ratio has been lately challenged due to the special pre-analytical prerequisites of PRA and lack of inter- 
laboratory reproducibility, it is not well recommended. In place of PRA, plasma active renin concentration (ARC) has been used to overcome these limitations. 16 Confirmation of the diagnosis is done by saline infusion test, fludrocortisone suppression test, oral salt loading, and captopril challenge test.

It is a major risk factor for death, and predicts cardiovascular incidents that can occur in future. ${ }^{4}$ So far no data is available about the frequency of PHA in Pakistani hypertensives. The aim of this study was to determine the frequency of PHA in young population of Pakistan who present with hypertension.

\section{METHODOLOGY}

After seeking permission from the Institution Review Board (IRB), this study was conducted from June 2016 to May 2017 at AFIP, Rawalpindi. Study design was cross-sectional. Sample size was calculated from given prevalence rate from formula of sample size estimation $(n=z 2 p(1-p) / d 2) .17$ Two hundred and fifty patients with hypertension (blood pressure of more than $140 / 90 \mathrm{~mm} \mathrm{Hg}$ ) of both genders, with age between 17-40 years were recruited in the study. Patients on anti-hypertensive medications, renal function derangement, pregnant females and those labelled with secondary hypertension were excluded. After taking consent from the subjects, sampling was done by nonprobability consecutive sampling technique.

Three milliliters venous blood was taken in EDTA vacutainers for plasma aldosterone and renin. Heparinized syringe was used to collect arterial blood sample for blood gases, $\mathrm{pH}$ and electrolytes (sodium, bicarbonate and potassium). Arterial blood was analysed on COBAS b221 by potentiometry; and bicarbonate levels were calculated by Henderson Hassel Balch equation. Plasma renin was done by sandwich chemiluminescence immunoassay on Diasorin Liason ${ }^{\circledR}$ and plasma aldosterone by ELISA (enzyme linked immunosorbent assay) on Biorad $\mathrm{PhD}{ }^{\mathrm{TM}}$ system. Sample for aldosterone and renin was collected from patient in morning in seated ambulatory position. All patients were on unrestricted salt intake. Hypokalemia found was corrected with oral potassium supplements. Saline infusion test was performed on patients having a positive screening test for primary hyperaldosteronism by intravenous administration of two liters of $0.9 \%$ isotonic saline over four hours (from 8 AM to $12 \mathrm{PM}$ ), while the patient was comfortably seated to check for aldosterone suppression. Aldosterone concentration, after four hours, below $139 \mathrm{pmol} / \mathrm{L}$ was considered as a normal response, whereas values above $277 \mathrm{pmol} / \mathrm{L}$ were consistent with primary aldosteronism.20 Aldosterone to renin ratio (ARR) was computed after measuring plasma aldosterone and plasma active renin concentration (ARC). This was used as a screening test for primary hyperaldosteronism. An ARR of more than $130 \mathrm{pmol} / \mathrm{mIU}$ was consistent with suspicion of primary hyperaldosteronism, while ARR below $100 \mathrm{pmol} / \mathrm{mlU}$ was suggestive of essential hypertension. 21

Statistical Package for Social Sciences (SPSS) version 24 was used for data analysis. Mean and standard deviations were calculated for all the parametric quantitative variables while frequencies with percentages were used for qualitative variables.

\section{RESULTS}

Out of 250 patients, $188(75.2 \%)$ patients gave consent for the study, out of which only $80(42.5 \%)$ were selected as they fulfilled the inclusion criteria. Out of these 80 patients, $68(85 \%)$ were males and $12(15 \%)$ were females. Mean diastolic blood pressure of all patients was $90.3 \pm 6.5 \mathrm{~mm}$ of $\mathrm{Hg}$ while mean systolic blood pressure was $142.7 \pm 10.5 \mathrm{~mm}$ of $\mathrm{Hg}$. Mean age of all the patients was $30.8 \pm 7.1$ years (Table I).

Among the studied subjects, eight $(10 \%)$ patients screened positive for primary hyperaldosteronism, and all were males. Seventy-two (90\%) patients were reported with essential hypertension, out of whom $60(83.3 \%)$ were males and $12(16.6 \%)$ were females (Figure 1). All eight patients with ARR $>130 \mathrm{pmol} / \mathrm{mlU}$ were subjected to saline infusion test for confirmation of primary hyperaldosteronism, and all showed failure of suppression of aldosterone after saline infusion, thus confirming the diagnosis (Table II).

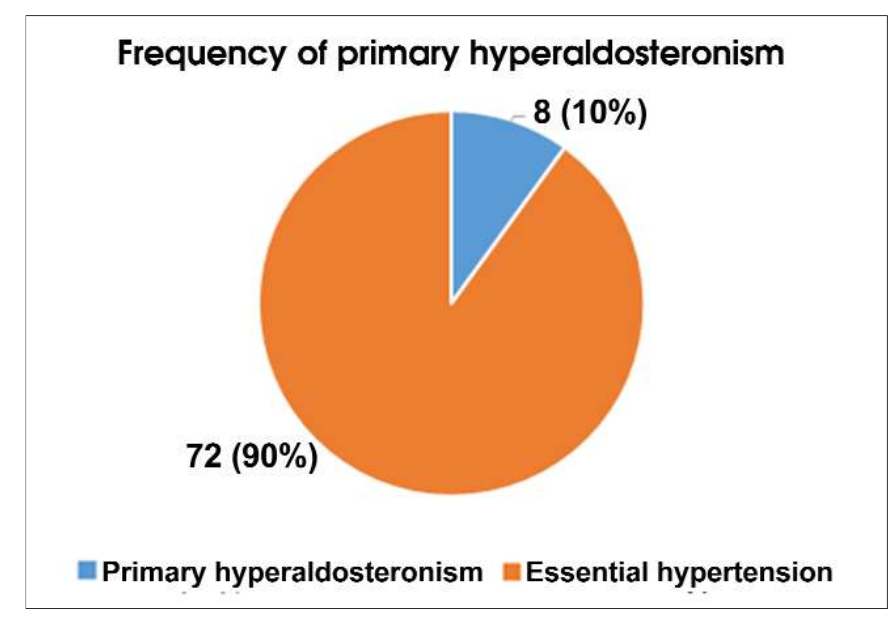

Figure 1: Pie chart showing frequency of primary hyperaldosteronism cases in a study population of 80 subjects.

Table I: Descriptive analysis of different study factors.

\begin{tabular}{|c|c|c|c|c|c|}
\hline & Age & Diastolic BP & Systolic BP & Serum Potassium & Serum Sodium \\
\hline All cases $($ Mean $+S D)$ years & $30.8 \pm 7.1$ & $90 \pm 6.5$ & $142.7 \pm 10.5$ & $4.23 \pm 0.6$ & $137.8 \pm 6.5$ \\
\hline With primary hyperaldosteronism (Mean+SD) $\mathrm{mmHg}$ & $29.25 \pm 7.1$ & $92.5 \pm 4.6$ & $143.12 \pm 11.6$ & $3.73 \pm 0.4$ & $140.6 \pm 6.3$ \\
\hline With essential hypertension (Mean+SD) $\mathrm{mmHg}$ & $30.97+7.1$ & $90.06 \pm 6.6$ & $142.70 \pm 10.5$ & $4.29 \pm 0.6$ & $137.5 \pm 6.5$ \\
\hline
\end{tabular}


Table II: Frequency with percentages of patients with positive screening test (ARR) for primary hyperaldosteronism.

\begin{tabular}{l|c|c}
\hline Number of patients & ARR $>130 \mathrm{pmol} / \mathrm{mlU}$ & $\begin{array}{c}\text { Failure to saline } \\
\text { infusion suppression test }\end{array}$ \\
\hline 80 & $8(10 \%)$ & $8(10 \%)$ \\
\hline
\end{tabular}

\section{DISCUSSION}

Primary (insuppressible) secretion of aldosterone is an underdiagnosed cause of hypertension. PHA is characterised by hypertension, hypokalemia and metabolic alkalosis, uninhibited secretion of aldosterone and a very low renin concentration. It is screened by PAC/PRC and screened cases are finally diagnosed following the confirmatory tests like the saline infusion test. ${ }^{18}$

Primary hyperaldosteronism cases found in $10 \%$ cases. All these positive patients were males. A very similar finding has been reported by a study conducted in Italy by Rossi et al., which is $11.2 \%$ without gender differences and same study population characteristics (e.g. age). ${ }^{14}$ A Greek study, conducted by Douma et al. in Aristotle University, reported a frequency of $11.3 \%$ of primary hyperaldosteronism, ${ }^{19}$ which is consistent with the present findings.

Roberto et al. documented a prevalence of $5.9 \%$ in Italy after confirmation by saline infusion test. 20 This difference can be explained by the fact that different ethnic groups and races have different expression of diseases; therefore, emphasizing on the fact that each population should be studied separately for the prevalence of a particular disease. 21

Douma et al. reported a mean age for primary hyperaldosteronism of $56.7 \pm 12.3$ years and that for essential hypertension was $56.3 \pm 12.3$ years, ${ }^{19}$ while in this study the mean age of patients having essential hypertension was $30.97 \pm 7.1$ years and of those with primary hyperaldosteronism was $29.25 \pm 7.1$ years. This difference can be explained by the fact that our study was based on young hypertensive population, while age was not a criterion in their inclusion.

Although these results project will serve as a preliminary data for future information and studies, but lack of genetic testing, single center study and a small sample size are the limitations. Therefore, the authors would recommend a metacentric study with an advanced study design and a bigger sample size for more authentic results.

\section{CONCLUSION}

Primary hyperaldosteronism is common in young hypertensive population. It should always be considered in young population who present with hypertension. Screening of the patients first with ARR and then confirmation by saline infusion test should be the protocol.

\section{REFERENCES}

1. Shrivastava SR, Shrivastava PS, Ramasamy J. The determinants and scope of public health interventions to tackle the global problem of hypertension. Int J Prev Med 2014; 5:807.

2. Sarafidis PA, Li S, Chen SC, Collins AJ, Brown WW, Klag MJ, et al. Hypertension awareness, treatment, and control in chronic kidney disease. Am J Med 2008; 121:332-40.

3. Mohan S, Campbell NR. Hypertension management: time to shift gears and scale up national efforts. Hypertension 2009; 53:450-1.

4. Johnson HM, Thorpe CT, Bartels CM, Schumacher JR, Palta M, Pandhi $\mathrm{N}$, et al. Undiagnosed hypertension among young adults with regular primary care use. J Hypertens 2014; 32: 65-74.

5. Saleem F, Hassali AA, Shafie AA. Hypertension in Pakistan: time to take some serious action. Br J Gen Pract 2010; 60: 449-50.

6. Bavishi C, Bangalore S, Messerli FH. Renin angiotensin aldosterone system inhibitors in hypertension: Is there evidence for benefit independent of blood pressure reduction? Prog Cardiovasc Dis 2016; 59:253-61.

7. Thethi T, Kamiyama M, Kobori $H$. The link between the reninangiotensin-aldosterone system and renal injury in obesity and the metabolic syndrome. Cur Hypertens Rep 2012; 14:160-9.

8. Choi M, Scholl UI, Yue P, Björklund P, Zhao B, Nelson-Williams C, et al. $\mathrm{K}+$ channel mutations in adrenal aldosterone-producing adenomas and hereditary hypertension. Science 2011; 331: 768-72.

9. Ma TK, Kam KK, Yan BP, Lam YY. Renin-angiotensinaldosterone system blockade for cardiovascular diseases: current status. Br J Pharmacol 2010; 160:1273-92.

10. Tsiavos V, Markou A, Papanastasiou L, Kounadi T, Androulakis II, Voulgaris $\mathrm{N}$, et al. A new highly sensitive and specific overnight combined screening and diagnostic test for primary aldosteronism. Eur J Endocrinol 2016; 175:21-8.

11. Ardhanari S, Kannuswamy R, Chaudhary K, Lockette W, Whaley-Connell A. Mineralocorticoid and apparent mineralocorticoid syndromes of secondary hypertension. Adv Chronic Kidney Dis 2015; 22:185-95.

12. Wang LP, Yang KQ, Jiang XJ, Wu HY, Zhang HM, Zou YB, et al. Prevalence of Liddle syndrome among young hypertension patients of undetermined cause in a Chinese population. $J$ Clin Hypertens 2015; 17:902-7.

13. Glover M, Ware JS, Henry A, Wolley M, Walsh R, Wain LV, et al. Detection of mutations in KLHL3 and CUL3 in families with FHHt (familial hyperkalaemic hypertension or Gordon's syndrome). Clin Sci 2014; 126:721-6.

14. Rossi GP, Bernini G, Caliumi C, Desideri G, Fabris B, Ferri C, et al. A prospective study of the prevalence of primary aldosteronism in 1,125 hypertensive patients. J Am Coll Cardiol 2006; 48:2293-300.

15. Loh KC, Koay ES, Khaw MC, Emmanuel SC, Young Jr WF. Prevalence of primary aldosteronism among Asian hypertensive patients in Singapore. J Clin Endocrinol Metab 2000; 85:2854-9.

16. Perschel FH, Schemer R, Seiler L, Reincke M, Deinum J, Maser-Gluth $\mathrm{C}$, et al. Rapid screening test for primary hyperaldosteronism: ratio of plasma aldosterone to renin 
concentration determined by fully automated chemiluminescence immunoassays. Clin Chem 2004; 50:1650-5.

17. Pourhoseingholi MA, Vahedi M, Rahimzadeh M. Sample size calculation in medical studies. Gastroenterol Hepatol Bed Bench 2013; 6:14.

18. Scholl UI, Healy JM, Thiel A, Fonseca AL, Brown TC, Kunstman JW, et al. Novel somatic mutations in primary hyperaldosteronism are related to the clinical, radiological and pathological phenotype. Clin Endocrinol 2015; 83: 779-89.

19. Douma S, Petidis K, Doumas M, Papaefthimiou P, Triantafyllou A,
Kartali $\mathrm{N}$, et al. Prevalence of primary hyperaldosteronism in resistant hypertension: a retrospective observational study. Lancet 2008; 371:1921-6.

20. Fogari R, Preti P, Zoppi A, Rinaldi A, Fogari E, Mugellini A. Prevalence of primary aldosteronism among unselected hypertensive patients: a prospective study based on the use of an aldosterone/renin ratio above 25 as a screening test. Hypertens Res 2007; 30:111-7.

21. Kebebew E. Ethnic specific differences in endocrine neoplasms: The role of susceptibility genes. Am J Surg 2018; 215:1060-1.

.......... 